defect $1.5 \mathrm{~cm}$ in length with a severe left-to-right shunt and wall motion abnormalities.

Inotropic support was started during the wait for surgical correction. Through a right ventricular approach, the ventricular septal defect was seen, with flattening of the flaps. In addition, there was severe dilatation of the right ventricle, with an hypokinetic area and a 3-cm contused region. The ventricular septal defect was closed with a 2-cm polytetrafluoroethylene patch (Figure 3). On echocardiography at discharge, there was no evidence of right or left ventricular dysfunction, and there were no signs of shunt. One year after the operation, the patient is free of symptoms and doing well.

\title{
Selective carotid cannulation at the neck: A satisfactory option for reoperation for aneurysms of the ascending aorta and arch
}

\author{
Gabriele lannelli, MD, Luigi Di Tommaso, MD, Mario Monaco, MD, Donato Triggiani, MD, and Nicola Spampinato, MD, \\ Naples, Italy
}

\section{W} e have evaluated the results of a modified Bachet technique in patients undergoing reoperation for aortic aneurysms. This technique was intended to reduce the risk of a cerebral dysfunction caused by prolonged deep hypothermic circulatory arrest ${ }^{1}$ and bleeding caused by resternotomy.

\section{Methods}

Patients. From June 1999 to December 2001, a total of 4 patients underwent reoperation for ascending aortic or aortic arch aneurysm with selective cold cerebroplegia by bilateral cannulation of the common carotid arteries at the neck, as partially described by Bachet and colleagues. ${ }^{2}$ A previous history of surgery on the ascending or aortic arch was present in all cases. A perianastomotic pseudoaneurysm was present at the proximal site in 1 patient and at the distal site in 3 . One patient had a contained rupture of a proximal perianastomotic aortic aneurysm, with sternal erosion and expansion into the subcutaneous tissue (Figure 1, A).

Surgical technique. Common carotid arteries were exposed at the neck and cannulated with a $12 \mathrm{~F}$ high-flow cannula without flange (Sarns-3M Health-Care, Borken, Germany; Figure 2, A). Cardiopulmonary bypass (CPB) was started by femoral cannulation, executing a $\mathrm{Y}$ junction along the arterial line to establish an antegrade flow, after replacement of the aortic arch (Figure 2, B). On reaching the desired temperature of $26^{\circ} \mathrm{C}$, femoral perfusion was interrupted, common carotid arteries were proximally

From the Department of Cardiac Surgery, University “Federico II," Naples, Italy.

Received for publication July 16, 2003; accepted for publication Sept 16, 2003.

Address for reprints: Gabriele Iannelli, MD, Via Santo Strato 8, 80121 Napoli, Italy (E-mail: gabrieleiannelli@libero.it).

J Thorac Cardiovasc Surg 2004;127:276-8

$0022-5223 / \$ 30.00$

Copyright @ 2004 by The American Association for Thoracic Surgery

doi:10.1016/j.jtcvs.2003.07.045 clamped, and the antegrade cerebral perfusion was accomplished by a centrifugal pump with independent line and heat-exchanger. A circulatory arrest of less than 3 minutes was induced at resternotomy, maintaining brain perfusion at a flow of $10 \mathrm{~mL} /(\mathrm{kg} \cdot \mathrm{min})$ and temperature at approximately $10^{\circ} \mathrm{C}$.

Pressure into the perfusion line was established at 200 to 250 $\mathrm{mm} \mathrm{Hg}$, corresponding to 60 to $70 \mathrm{~mm} \mathrm{Hg}$ in the carotid arteries, as described by Bachet and colleagues. ${ }^{2}$ The ascending aorta and the arch were opened. The descending aorta was internally occluded with a Foley catheter, the subclavian artery was clamped to avoid steal phenomenon, and the CPB was restored to perfuse the lower half of the body at a flow greater than $500 \mathrm{~mL} / \mathrm{min}$. The left ventricle was vented through the right superior pulmonary vein. Antegrade intermittent cold blood cardioplegia was induced directly through the coronary ostia. When the distal aortic anastomosis was accomplished, we removed the Foley catheter, placed a proximal clamp on the vascular graft, vented the air, and reestablished the systemic antegrade blood flow through a side branch of a T-arm collagen-coated graft (Intergard; Hemabridge-Intervascular, La Ciotat, France). The extent of aortic replacement included ascending aorta and hemiarch replacement in 2 of the patients and complete ascending aorta and total arch replacement in the remaining 2, with 1 requiring a cuff of the epiaortic vessels and the other separate brachiocephalic and left carotid artery reimplantation (Figure 1, B).

The left subclavian artery was not involved in the aneurysm. The cerebral perfusion was interrupted, the carotid arteries were unclamped, and the carotid cannulas were removed. During the rewarming period we performed the proximal anastomosis and removed the graft clamp; at that time the air was completely vented and the CPB was progressively discontinued.

\section{Results}

The CPB time ranged between 89 and 125 minutes, whereas the antegrade cerebral perfusion time ranged between 37 and 76 minutes. One patient (25\%) died of low cardiac output syndrome in the postoperative period. None of the patients had major neurologic dysfunction with evidence of focal or general deficit, and only 1 patient had a temporary neurologic dysfunction. A patient with excessive bleeding (1750 $\mathrm{mL} / 36$ hours) and requiring pro- 

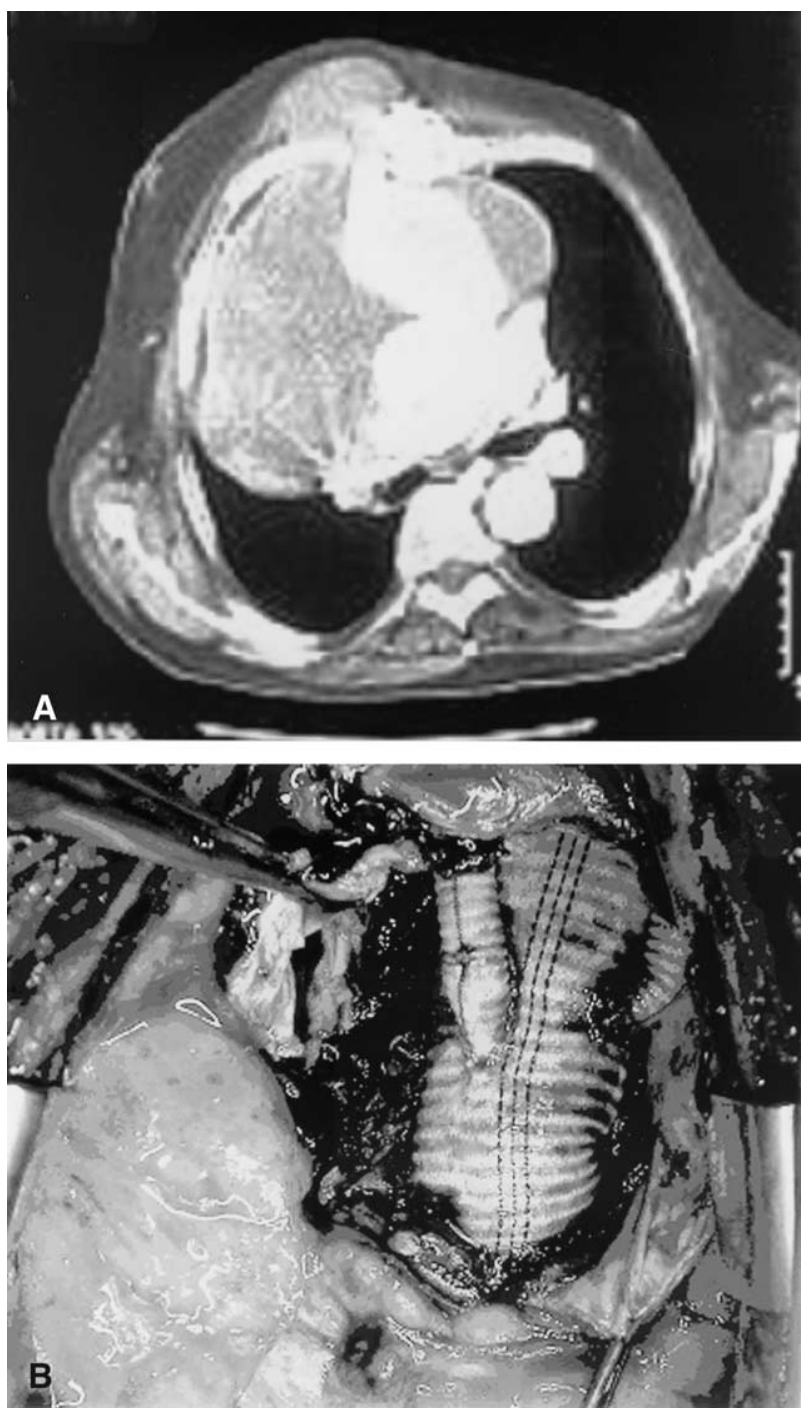

Figure 1. A, Angiographic CT scan showing sternal erosion and expansion of perianastomotic false aneurysm into subcutaneous tissue. B, Total replacement of ascending aorta and arch with separate brachiocephalic and left carotid artery reimplantation in same patient.

longed ventilation (11 days) had acute renal failure after the operation and underwent 12 days of hemodialysis.

\section{Discussion}

Drawbacks to the deep hypothermic circulatory arrest method include limited brain preservation time, a prolonged period of CPB to rewarm the patient, and high risk of coagulative and respiratory complications. ${ }^{1}$ In addition, the effectiveness of the retrograde cerebral perfusion remains controversial ${ }^{3,4}$. Even though the opening of the aortic arch washes out the air and solid debris from the cerebral arteries, and the safe limit of circulatory arrest is longer than with deep hypothermic circulatory arrest, complications related to deep hypothermia and cerebral edema caused by high venous pressure may occur. ${ }^{4}$
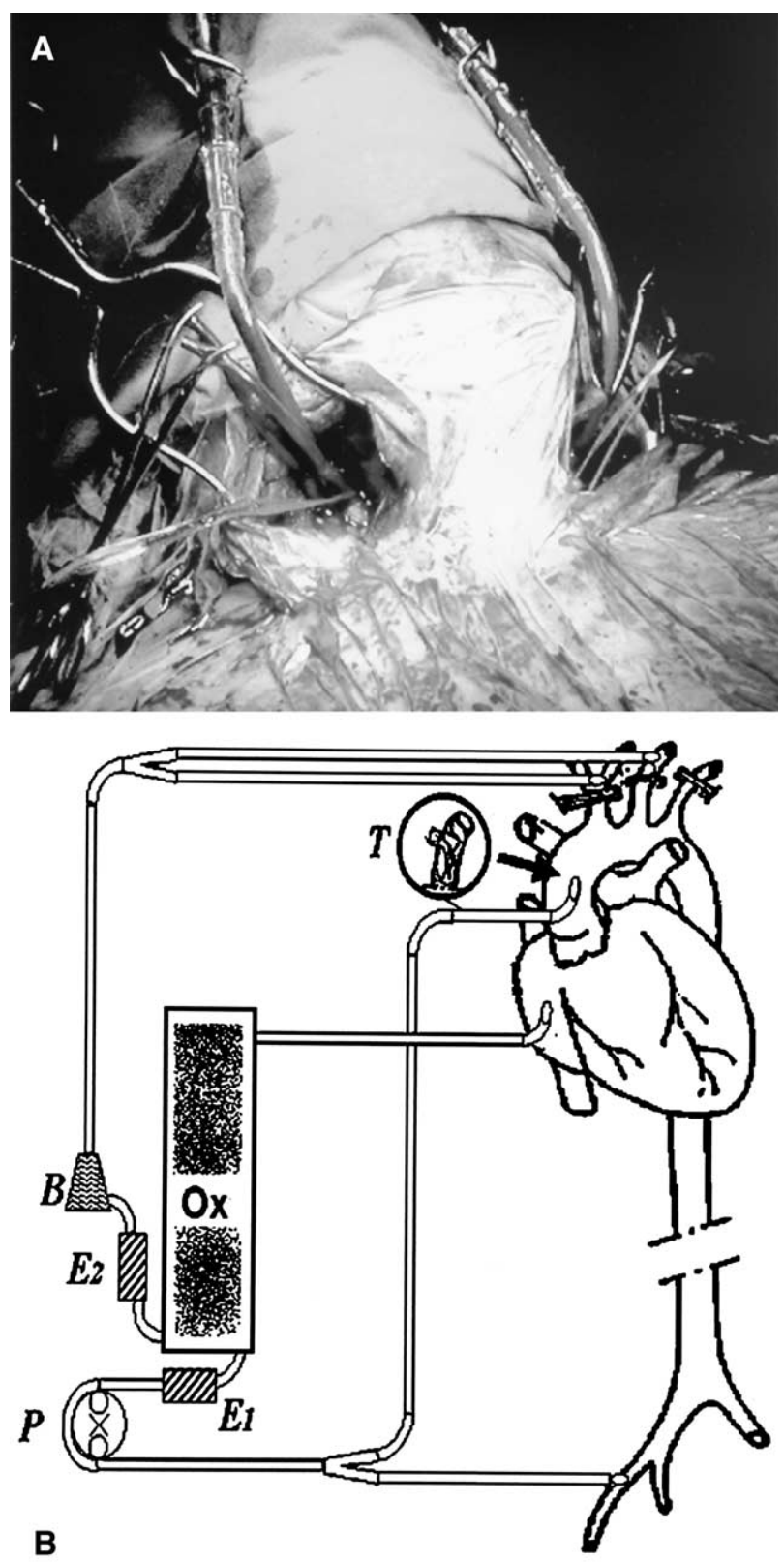

Figure 2. A, Common carotid arteries exposed and cannulated at neck. B, Perfusion circuit. $T$, T-arm graft (placed at arrow); $B$, centrifugal pump for cerebral circuit; $0 x$, membrane oxygenator; $E 2$, extra heat exchanger for cerebral circuit $\left(10^{\circ} \mathrm{C}\right) ; P$, roller pump for main circuit; $E 1$, extra heat exchanger for main circuit $\left(28^{\circ} \mathrm{C}\right)$.

Antegrade cerebral perfusion provides greater protection of the brain, thus avoiding deep hypothermia and prolonged CPB. ${ }^{2,5}$ This technique, accomplished by internal cannulation of the brachiocephalic or left common carotid artery (per Kazui and coworkers ${ }^{5}$ ) or by external cannulation of both carotid arteries (per Bachet and colleagues ${ }^{2}$ ), is recommended for patients who have already undergone an operation of the ascending aorta or aortic arch. We believe that the 
proposed modification of the Bachet technique is a safe and reproducible procedure that can avoid the risk of catastrophic bleeding and irreversible cerebral complications even in patients who are candidates for reoperation for large aortic arch aneurysms.

\section{References}

1. Svensson LG, Crawford ES, Hess KR, Coselli JS, Raskin S, Shenaq SA, et al. Deep hypothermia with circulatory arrest. Determinants of stroke and early mortality in 656 patients. J Thorac Cardiovasc Surg. 1993; 106:19-31.

2. Bachet J, Guilmet D, Goudot B, Termignon JL, Teodori G, Dreyfus G, et al. Cold cerebroplegia. A new technique of cerebral protection during operations on the transverse aortic arch. J Thorac Cardiovasc Surg. 1991;102:85-94.

3. Ueda Y, Miki S, Kusuhara K, Okita Y, Tahata T, Yamanaka K. Deep hypothermic systemic circulatory arrest and continuous retrograde cerebral perfusion for surgery of aortic arch aneurysm. Eur J Cardiothorac Surg. 1992;6:36-42.

4. Griepp RB, Juvonen T, Griepp EB, McCollough JN, Ergin MA. Is retrograde cerebral perfusion an effective means of neural support during deep hypothermic circulatory arrest? Ann Thorac Surg. 1997; 64:913-6.

5. Kazui T, Washiyama N, Muhammad BA, Terada H, Yamashita K, Takinami M, et al. Total arch replacement using aortic arch branched grafts with the aid of antegrade selective cerebral perfusion. Ann Thorac Surg. 2000;70:3-9.

\title{
Aortic arch aneurysm with dissection in Cushing syndrome
}

\author{
Hisato Takagi, MD, PhD, Maiko Furukawa, MD, Yukio Umeda, MD, PhD, Yukiomi Fukumoto, MD, PhD, \\ Naomasa Yoshida, MD, Takuya Yamada, MD, PhD, and Yoshio Mori, MD, PhD, Gifu, Japan
}

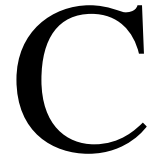

ushing syndrome is caused by glucocorticoid excess and has been known as a risk factor for dissecting aortic aneurysm. To our knowledge, however, only one case of dissecting aortic aneurysm with Cushing syndrome has been found in the English literature. ${ }^{1}$ The authors describe a case of nondissecting true aneurysm of the aortic arch and Stanford type B chronic aortic dissection with Cushing syndrome caused by adrenal cortical adenoma.

A 55-year-old woman, whose moon facies had been pointed out 3 years before, was recently given a diagnosis of Cushing syndrome. Hypertension, glucose intolerance, and proximal muscle weakness were observed. The plasma cortisol concentration was increased to $23.7 \mu \mathrm{g} / \mathrm{dL}(4.0-18.3 \mu \mathrm{g} / \mathrm{dL})$ and was not suppressed by the administration of 1 and $8 \mathrm{mg}$ of dexamethasone. The plasma adrenocorticotropic hormone concentration was less than 5.0 $\mathrm{pg} / \mathrm{mL}$ (7.4-55.7 pg/mL). Computed tomographic scans (Figure 1) disclosed a saccular nondissecting true aneurysm of the distal aortic arch with a mural thrombus, a Stanford type B aortic dissection, and a left adrenal tumor $32 \mathrm{~mm}$ in diameter. There was a history of severe back pain 5 months before, and the dissection was considered to have occurred at that time. The patient simultaneously underwent left adrenalectomy through a laparotomy and graft replacement of the distal aortic arch and the proximal de-

\footnotetext{
From the First Department of Surgery, Gifu University School of Medicine, Gifu, Japan.

Received for publication Aug 11, 2003; accepted for publication Aug 21, 2003.

Address for reprints: Hisato Takagi, MD, PhD, First Department of Surgery, Gifu University School of Medicine, 40 Tsukasa, Gifu 500-8705, Japan (E-mail: h-takagi@cc.gifu-u.ac.jp).

J Thorac Cardiovasc Surg 2004;127:278-9

$0022-5223 / \$ 30.00$

Copyright (C) 2004 by The American Association for Thoracic Surgery

doi:10.1016/j.jtcvs.2003.08.022
}

scending thoracic aorta under partial cardiopulmonary bypass through a left thoracotomy. The dissecting intima was thickened, and therefore the dissection was diagnosed as chronic. Pathologic examination of the adrenal tumor showed cortical adenoma without atypical cells. The elastic fibers of the media was maintained in the dissecting aorta but disrupted in the nondissecting true aortic aneurysm. Although tracheostomy was required postoperatively because of muscle weakness, the patient is doing well 3 months after the operation.

Although Cushing syndrome has been known as a risk factor for dissecting aortic aneurysm, the association of these 2 entities is extremely rare. In 1935, Lawrence and Zimmerman ${ }^{1}$ described a 44-year-old man who presented with the clinical features of Cushing syndrome of pituitary basophilism and died as the result of a ruptured dissecting aortic aneurysm. Although Suzuki and associates $^{2}$ have reported a case of a 31-year-old man who suddenly died of ruptured dissecting aortic aneurysm 5 years after pituitary microsurgical treatment for Cushing disease, the aneurysm might not be directly related to the Cushing disease because of the absence of hormonal abnormalities, including plasma adrenocorticotropic hormone and cortisol levels, for 2 years before the patient's death. The report of Lawrence and Zimmerman ${ }^{1}$ has been the only case of dissecting aortic aneurysm with Cushing syndrome in the English literature. On the other hand, Steffee and Snell ${ }^{3}$ have reported that dissecting aortic aneurysm is produced in hamsters by cortisone acetate. In the media of the aorta adjacent to cortisoneinduced dissecting aneurysm in hamsters, Valigorsky ${ }^{4}$ has demonstrated the occurrence of cellular metaplastic transformation of smooth muscle cells to fibroblast-like cells. It is suggested that hypercortisolemia in Cushing syndrome affects the aortic smooth muscle cells and produces a dissecting aortic aneurysm.

Yoshitomi and colleagues ${ }^{5}$ have presented a 26-year-old woman with splenic artery aneurysm and Cushing syndrome, and it has been speculated that chronic hypercortisolemia caused by the syndrome was causally related to the aneurysm. Although Reilly and associates ${ }^{6}$ have established the role of hydrocortisone in the induc- 